REVISTA DE DERECHO UNED, NÚM. 14, 2014

\title{
REVISIÓN DE LOS VALORES IMPLICADOS EN EL PROCESO DE EMANCIPACIÓN INDIVIDUAL EN LA SOCIEDAD TRANSNACIONAL
}

\author{
REVISION OF THE VAWES INVOLVED IN INDIVIDUAL \\ EMANCIPATION WITH IN A TRANSVERSE SOCIETY
}

\author{
Prof. Dr. D. David E. PÉrez GonzÁlez \\ Universidad de La Laguna
}

Resumen: Los movimientos migratorios que caracterizan a la sociedad de nuestros días obligan a una revisión de la función que cumplen los valores jurídicos. La dignidad constituye el presupuesto para la cabal comprensión de los derechos de todos, nacionales y extranjeros. Las desigualdades en el punto de partida deberán ser corregidas con un planteamiento sustantivo del valor de la solidaridad que incida en la necesidad del cumplimiento de los deberes que a todos incumben con miras a la realización de los derechos de los demás. Ello supone superar la visión estrictamente económica del fenómeno globalizador para asumir una globalización basada en el respeto universal de los derechos humanos. La convivencia social entre individuos que ven igualmente satisfechas sus necesidades fundamentales constituye el reto a alcanzar.

Palabras clave: Dignidad, solidaridad, globalización, no discriminación, convivencia.

Abstract: The migratory movements typical of our days society force us to make a reexamination about the operativity of juridical vawes. Dignity constitures the main budged for the exat comprehension of everyone rights both national and foreign. Inequality from the starting point must corrected with a significant idea of solidaritys vawe that affects in the necesity of fullfilmen obligations for everyone 
to look on to the others rights. That implies superation on a strict economy vision of globalitation and adopt a globalitation based on universal respect socializing among individuals that see equally sastisfied their basic necesitys thats the challenger to overtake.

Key words: Dignity, solidaritys, globalitation, non-discrimination, coexistence.

Recepción original: 30/01/2014

Aceptación original: 27/02/2014

Sumario: I. La implicación estructural de la dignidad con los derechos humanos. II. La igualdad como premisa. III. La función de la solidaridad. IV. Los postulados del universo global. IV.1. Planteamiento. IV.2. Posturas a favor. IV.3. Posturas en contra. V. La redefinición del sentido de la globalización. VI. A modo de conclusión. VII. Bibliografía.

\section{LA IMPLICACIÓN ESTRUCTURAL DE LA DIGNIDAD CON LOS DERECHOS HUMANOS}

La sustantividad de la dignidad humana en el entramado axiológico de los sistemas jurídicos está fuera de discusión. Por un lado es la condición necesaria para la misma representación de la idea de los derechos. Como bien se ha dicho, «el alcance de la dignidad del hombre representa la piedra angular del edificio de los derechos humanos» ${ }^{1}$. Por otro lado, es el punto de referencia del resto de los valores superiores y también el punto de partida ${ }^{2}$ en cuanto que de alguna manera los integra en su existencia constituyendo cada uno de ellos su proyección inmediata. Es la postura que defiende Eusebio Fernández cuando señala que la dignidad humana "precisa para su delimitación de otros valores como la autonomía, la seguridad, la libertad o la igualdad, valores que se encuentran reconocidos en la actual noción de los derechos humanos fundamentales» ${ }^{3}$.

Entre las notas definitorias de los derechos humanos destaca en este punto el carácter irrenunciable que enlazado con el valor digni-

${ }^{1}$ Vergés Ramírez, Salvador, Derechos humanos: Fundamentación, Tecnos, Madrid, 1997, pág. 84.

2 Sobre los valores superiores véase PeCES-BARBA, Gregorio, Los valores superiores, Tecnos, Madrid, 1984; PAREJo Alfonso, Luciano, Constitución y valores del ordenamiento, Ceura, Madrid, 1991; Llamas CAScón, Ángel, Los valores jurídicos como ordenamiento material, Universidad Carlos III, Madrid, 1993.

${ }^{3}$ FERnÁNDEZ García, Eusebio, «Estado, sociedad civil y democracia», en AA. VV., Valores, derechos y Estado a finales del siglo XX, Dykinson, Madrid, 1996, pág. 157. 
dad enmarca a los individuos en el estatus de protección que le proporciona los cimientos necesarios que requiere para desenvolverse en sociedad en un cierto nivel de amparo legal. El carácter universal de los derechos humanos obliga a destacar la especial situación de vulnerabilidad en que se encuentran los inmigrantes que aceden a un Estado que muchas veces no les recibe con el respeto que merecen como miembros de la comunidad humana. La apelación a la dignidad como fundamento de los derechos se impone a este respecto, procurando una protección no discriminatoria a todos los que comparten esa misma condición humana ${ }^{4}$.

Aunque hoy en día resulta incuestionable adjetivar con el término dignidad a los seres humanos (no hay seres humanos indignos, por lo menos indignos de entrada), desgraciadamente los ataques que al individuo se producen en la práctica de muchos lugares del mundo son una constante, pues la vulneración de derechos y el despojo de la dignidad son una realidad palpable que parece superar cualquier dimensión temporal.

Cuando focalizamos esta postura sobre la inmigración pudiera parecer que no hay cabida para diferente tratamiento y por ende los extranjeros no deben diferenciarse de los ciudadanos nacionales, porque ambos tienen su base en la dignidad, siendo ésta, la diferencia entre nacional y extranjero, una característica que no debe afectar a los derechos humanos. De ahí que se patrocine como estandarte el ideal por el que el extranjero no debe ser excluido del disfrute del derecho a la dignidad por las limitaciones de carácter político que establezcan los diferentes Estados. Pero alejados de meras declaraciones de voluntad hoy los poderes públicos tienen tanta fuerza que pueden incluso entrar, eso sí por vía indirecta, a matizar el concepto de dignidad a través de las limitaciones que por medio de disposiciones legislativas establecen $^{5}$. Esta hipótesis es asumida por Robert Spaemann en su estudio Sobre el concepto de dignidad humana cuando afirma que «lo que habi-

${ }^{4}$ Ya que, la dignidad y «solamente ella cumple los requisitos necesarios para dar soporte a los derechos del hombre, porque ella integra el derecho natural, dándole una nueva impostación, por una parte, y esquivando los escollos en los que encallaba aquél, por otra», Vergés RamíreZ, Salvador, Derechos humanos... cit., pág. 86.

${ }^{5}$ En esa línea, apunta Peces-Barba «Las limitaciones derivadas de conceptos como el de soberanía o el de representación son obstáculos prácticos, restos de una cultura jurídica y política pasada, que justifican la limitación de algunos derechos que facilitan la participación en la formación de la voluntad estatal. Sin embargo, no parece razonable, ni se encuentra justificado que se construya un fundamento de derechos que no arranque de una visión cosmopolita y que excluya a los extranjeros, como si su dignidad se limitase al entrar en el ámbito de la organización del poder político», Peces-Barba, Gregorio, Curso de derechos fundamentales. Teoría general, Universidad Carlos III de Madrid, Boletín Oficial del Estado, Madrid, 1995, pág. 433. 
tualmente se dice, que todos los hombres participan igualmente de la dignidad humana, sólo es correcto si la expresión dignidad humana designa ese mínimo de dignidad por debajo del cual nadie debe caer» ${ }^{6}$.

Si consecuentemente, y basándonos en la esencia de tal argumento, se pretendiera materializar esta teoría, el extranjero, por mucho que esté en un lugar fuera de su entorno en el que no se le reconocen una serie de derechos de carácter político, no debe mantener su situación por debajo de lo que se considera ese mínimo de dignidad humana, que, a su vez, lo sitúa como legítimo titular para el reconocimiento de unos derechos, los derechos humanos ${ }^{7}$.

Este testimonio debe ser analizado desde el prisma de una sociedad cambiante. Nadie discute que en la actualidad las sociedades están en continua evolución lo que irremediablemente exige a los ordenamientos jurídicos su acomodo con la realidad existente en cada momento. Contexto éste que en muchas ocasiones supera las regulaciones jurídicas vigentes dando lugar a que la realidad siempre cree nuevas situaciones, las cuales exigen una regulación normativa a fin de evitar que aparezca la figura de la laguna del derecho. Este cambio de escenario extrapolado al valor que aquí referenciamos reivindica su consagración en todos los sistemas jurídicos con el objetivo final de que la dignidad avale las disposiciones legales que se aprueben y que al menos inspire los mandatos normativos que impulsen cumplir con el principio de plenitud del ordenamiento jurídico ${ }^{8}$. El reconocimiento puntual de los derechos humanos, si no va acompañado de los instrumentos necesarios para accionar su contenido obligatorio, pondría al descubierto lagunas jurídicas, vacios de regulación, puesto que reflejaría la falta de regulación de algo que la propia declaración del derecho en cuestión vendría a imponer? .

${ }^{6}$ Spaemann, Robert, «Sobre el Concepto de Dignidad Humana», en Persona y Derecho, n. ${ }^{\circ}$ 19, Pamplona, 1988, pág. 23.

${ }^{7}$ A este respecto, se observa como «los derechos están reconocidos y garantizados en el Estado de Derecho, reconocimiento y garantía que, desde el punto de vista jurídico, se hace más intensa a partir de las consecuencias normativas de la Constitución, ANSUÁTEgui RoIG, Francisco J., «La relación entre los derechos fundamentales y el Estado de Derecho: dimensiones y consecuencias», en Anuario de Filosofía del Derecho, Tomo XXIII, 2006, pág. 197.

${ }^{8}$ Lo mismo que sucede con una determinada situación que se origina en la vida social ocurre en el reconocimiento de derechos fundamentales, los cuales, como antes dijimos, encuentran su base en la dignidad. Véase Vergés RAMíREz, Salvador, Derechos humanos... cit., pág. 86, cuando asevera que «lo más relevante aún es el carácter dinámico de la dignidad, que cumple con creces el contenido de la eficacia, exigida a la función de la base de los derechos humanos».

${ }_{9}^{9}$ FERRAJOLI, Luigi, «Derechos fundamentales», en FerRajoli, L., El fundamento de los derechos fundamentales (edición de A. de Cabo y G. Pisarrello), Trota, Madrid, 
Sobre esta línea, la caracterización de la dignidad como valor dinámico no puede dejar de lado otro de los principios al que está íntimamente ligado, y sobre el que profundizaremos en su análisis más adelante, nos referimos a la solidaridad. Característica ésta, dinámica y en consecuencia modulable, que tiene su máximo exponente en los trasvases de los flujos migratorios al provocar necesariamente cambios en las sociedades de acogida. Estas repercusiones sociales encuentran desde la perspectiva de la dignidad y de la solidaridad su acomodo en la estructura de grupo, que alejada de una estricta consideración individual, vela porque el movimiento de personas entre diferentes lugares, aparte de ser muy numeroso, comporte una indudable repercusión social en el lugar de llegada que dificulta la convivencia $^{10}$.

\section{LA IGUALDAD COMO PREMISA}

La igualdad como elemento esencial en el análisis de los derechos humanos, de la misma forma que ocurre con los demás valores a los que está íntimamente relacionado ${ }^{11}$, ha suscitado en materia de extranjería muchos problemas para los cuales no es fácil encontrar una rápida solución. Ya aludimos, cuando hablábamos de la dignidad, que el individuo que no tenga ese mínimo de dignidad humana está en una precaria condición para su desarrollo personal. Pues consagrar un mínimo denominador común para el establecimiento de un mis-

2001, pág. 26, señala que «la ausencia de las correspondientes garantías equivalentes (...) a una inobservancia de los derechos positivados estipulados por lo que consiste en una indebida laguna que debe ser colmada por la legislación».

${ }^{10}$ A esta teoría se unen varios de los autores que han tratado el tema, destacando Vergés, pues afirma que «el progreso de la dignidad de hombre tiene una dimensión no sólo personal, sino también social, por cuanto que el hombre es un ser individual, a la vez que comunitario, sin solución de continuidad. La dignidad, pues, en su evolución progresiva, parece redimensionarse, al asentar plaza de ciudadanía en la vida público-social», VERGÉs RAMíREZ, Salvador, Derechos humanos... cit., pág. 149. Esta cuestión también es defendida por Peces-Barba, pero en este caso identificando a la dignidad con otros valores como la moralidad, la independencia o la autonomía en relación con un derecho, el derecho al desarrollo. Afirma que «la dignidad como raíz de la moralidad, y la independencia o la autonomía como su meta, serían compatibles con la pretensión moral del derecho al desarrollo, como derechos de los grupos, de los pueblos y de las naciones, sólo como expresión de las pretensiones de los individuos que los componen», PECEs-BARBA, Gregorio, Curso de derechos fundamentales... cit., pág. 189.

${ }^{11}$ Pérez Luño, Antonio E., «Sobre los valores fundamentadores de los derechos humanos», en PECEs-BARBA, G., El fundamento de los derechos humanos, Debate, Madrid, 1989, págs. 279-288, parece reconocer, sin embargo, una cierta autonomía a la igualdad como valor fundante de determinados derechos. 
mo nivel de reconocimiento de facultades a los individuos por muchas diferencias de etnia, cultura, religión, raza, sexo, etc, que existan entre ellos, concluye en un trato igualitario y, por lo tanto, un mismo reconocimiento óptimo de dignidad.

Este argumento lo evidencia Peces-Barba al instituir que «la igualdad permite un trato adecuado al común carácter de la dignidad humana, al hecho de que todos los hombres estén en condiciones equilibradas para participar en el dinamismo de la libertad, usando ilustradamente los medios que proporciona la libertad social, política y jurídica a través de los derechos fundamentales» ${ }^{12}$. Destaca en este punto el instrumento normativo (Declaración) que a partir del 20 de noviembre de 1963, fecha en la que fue aprobada por la resolución 1904 de la 18. ${ }^{a}$ Asamblea General de Naciones Unidas, se pugna en la esfera internacional por la eliminación de todas las formas de discriminación racial. Proclama la declaración en su artículo $1 .^{\circ}$ "La discriminación entre los seres humanos por motivos de raza, color u origen étnico es un atentado contra la dignidad humana y debe condenarse como una negación de los principios de la carta de NU, una violación de los derechos humanos y las libertades fundamentales proclamadas en la declaración universal de los derechos humanos, un obstáculo para las relaciones amistosas y pacíficas entre las naciones y un hecho susceptible de perturbar la paz y la seguridad entre los pueblos».

\section{LA FUNCIÓN DE LA SOLIDARIDAD}

La incidencia de la solidaridad en relación con los derechos humanos resulta especialmente llamativa en nuestros días. En particular al ciudadano de un mundo globalizado se le garantizan una serie de derechos basados en la solidaridad colectiva ${ }^{13}$, sin la cual este sujeto, que se encuentra muchas veces en una situación de desventaja con respecto a sus semejantes, se ve inevitablemente perjudicado. De ahí que se haya podido decir que «el punto de partida de la solidaridad es el reconocimiento de la realidad del otro y la consideración de sus problemas como no ajenos, sino susceptibles de resolución con intervención de los poderes públicos y de los demás» ${ }^{14}$. Esto lleva irremediablemente a una posición en la que no hay cabida a la paradójica

12 Peces Barba, Gregorio, Curso de derechos fundamentales... cit., pág. 247.

${ }^{13}$ Véase en este sentido, Rosales, José M. ${ }^{\mathrm{a}}$ "Del altruismo espontáneo a la solidaridad organizada», en Rubio Carrecedo, J., Rosales, J. M. y Toscano Méndez, M., Educar para la ciudadanía: perspectivas ético-politicas, Contrastes. Revista Interdisciplinar de Filosofía, suplemento 8, 2003.

${ }^{14}$ Peces Barba, Gregorio, Curso de derechos fundamentales... cit., pág. 270. 
situación que se genera que por el hecho de que tener una raza o un origen diferente, sea determinante para recibir un tratamiento desigual con respecto a los que tienen reconocida la condición de ciudadanos nacionales. Ciudadanos que en buena lógica sí que tienen acceso a la solución de esas necesidades básicas sin ningún tipo de esfuerzo, sino de forma automática y sólo por el hecho de ser nacionales del país de que se trate. A diferencia de esos individuos, los inmigrantes, que ya tienen desde el momento de entrada en el país marcadas diferencias, sólo pueden acceder a los bienes que permiten satisfacer las necesidades básicas mediante el reconocimiento de derechos, que nos obliga traer a la memoria los elementos configuradores de la solidaridad que implican la consideración de los problemas de los otros como propios, pero, no sólo por parte de los poderes públicos, sino también de los ciudadanos individualmente considerados $\mathrm{y}$ de los grupos que forman.

De igual modo, que la solidaridad en su alcance internacional exige que culturas muy diferentes desde su base y configuración utilicen un mismo criterio con idéntico valor para resolver cuestiones de muy variada índole, en salvaguarda de una sociedad multicultural, la exigencia que conlleva inevitablemente a una mayor intercomunicación entre los pueblos se convierte en perentoria en el escenario actual. Pueblos cada día más en constante evolución, puesto que las sociedades cambiantes originan nuevas situaciones, que reclaman a la par nuevas regulaciones jurídicas propias de una sociedad globalizada. Fiel reflejo de ello es lo que ha acontecido a finales del siglo pasado en nuestro país, donde el aumento y desarrollo de la economía, unido al nivel de vida que alcanzó el ciudadano medio provocó que España se convirtiera, principalmente en los últimos años del siglo XX y principios del XXI en un país receptor de inmigrantes o también en frontera de entrada a lo que se ha llamado el paraíso europeo, que consecuentemente acarreó que el cumplimiento de muchas de las exigencias de esos nuevos sujetos demandantes de derechos solamente pudieran satisfacerse por vía de la solidaridad.

Por medio de una de las características más significativas de los derechos humanos, la universalidad se capacita a los individuos para reivindicar unos derechos que se consideran básicos y esenciales para todo ser humano, independientemente de su nacionalidad y cultura, que unida a la solidaridad internacional permiten alcanzar muchos de los objetivos armonizantes que rompan las marcadas diferencias que existen entre una multitud de lugares, al considerar que «el valor solidaridad es un instrumento clave para la comprensión de la aplica- 
ción y para la interpretación de los derechos» ${ }^{15}$, y por lo tanto como medio de conocimiento lingüístico y como medio de averiguación del significado de los derechos de ineludible aplicación. La solidaridad constituye en este sentido un elemento clave para la realización material del principio de igualdad. No puede caber una igualdad real sin la acción solidaria de los demás en pos de la satisfacción de sus exigencias. Satisfacción que algunos han llevado al plano de la identificación de los derechos al interpretar que todos han de encontrarse en condiciones idénticas como consecuencia de la acción solidaria común para participar en el consenso que permite una acción solidaria común ${ }^{16}$.

Consagrado de este modo el principio de igualdad es necesario hacer una aclaración respecto al mismo, ya que el establecimiento del derecho a la igualdad no significa tratar de manera idéntica a todo el mundo, sino, tratar de forma igualitaria a los que están en condiciones de igualdad. Esto implica consecuentemente, tratar desigualmente a los que no sean iguales. Por lo que, según esta tesis, para que una persona reciba un trato igualitario a otra es requisito indispensable que estén en una situación de igualdad y tengan las mismas condiciones ${ }^{17}$. Hecho que no ocurre con los extranjeros que entran en un determinado país porque ya, desde el principio, tienen un elemento que los diferencia, que es su condición de no nacional de ese país, criterio sobre la base del cual pueden recibir un trato diferente en alguna de sus actuaciones, sobre todo en las de carácter político y administrativo. A pesar de ello ya, «el derecho internacional tradicional reconoció desde sus comienzos la obligación de los Estados de tratar a los extranjeros de acuerdo a un standard mínimo de civilización y justicia» ${ }^{18}$. En su evolución, el derecho internacional en lo relacionado con los derechos humanos, ha pasado por varias etapas teniendo en cada una de ellas una visión particular sobre el asunto y dependiendo también del lugar en el que se desarrolla. Por ejemplo disiente al respecto un sector doctrinal porque «los Estados latino-americanos no aceptaron la teoría del standard mínimo como fuera formulada en

${ }^{15}$ Ibídem, pág. 282.

${ }^{16}$ ARA PINILla, Ignacio, «El significado dela solidaridad como valor fundante de los derechos humanos», en A. de Julios Campuzano (editor), Dimensiones jurídicas de la globalización, Dykinson, Madrid, 2007, págs. 55-79.

${ }_{17}$ Véanse a este respecto las diferentes perspectivas que sobre el particular ofrecen los trabajos contenidos en García SAN Miguel, Luis, El principio de igualdad, Dykinson, Madrid, 2000.

${ }_{18}$ Buergenthal, Thomas, Grossman, Claudio, Nikken, Pedro, Manual Internacional de Derechos Humanos, Instituto Interamericano de Derechos Humanos, Editorial Jurídica Venezolana, Caracas, San José, 1990, pág. 14. 
el derecho tradicional $»^{19}$, por lo que "como contrapartida al standard mínimo, la doctrina latinoamericana formuló el principio de no discriminación. Según este principio, los extranjeros debían recibir el mismo trato que correspondía a los nacionales (...). Si bien la doctrina de no discriminación fue positiva en cuanto destacó el valor de no diferenciar entre nacionales y extranjeros, su rechazo a la no discriminación no era sobre la base de identificar derechos válidos para todos sino que bastaba que a todos se tratara por igual, aunque fuera igual de mal» ${ }^{20}$.

Es evidente, que no se puede aceptar la aplicación de un principio fundamental desde la perspectiva de los derechos humanos como lo hizo la doctrina latinoamericana, pues siempre que hablamos de igualdad, como ya hemos recalcado, este principio está relacionado con los otros valores que deben regir en la vida de un hombre y concretamente con el de la dignidad inmanente a cada cual. Siendo indispensable que existiera lo que llamábamos un mínimo de dignidad humana, la cual, sería incompatible con un trato igualitario malo; es decir, con un trato que por muy igualitario que fuera no respetara unas condiciones mínimas del ser humano. Por lo tanto, en estos casos se defiende una postura que venga avalada por un tratamiento igualitario que a su vez garantice el alcance de los mínimos elementos consustanciales al valor que representa la dignidad humana ${ }^{21}$.

Nuestro país al constituirse como un Estado social y democrático de derecho ampara la defensa de los valores enunciados porque «mientras que con el Estado de derecho se quiere desplegar una idea de libertad al margen de las actuaciones estatales, el Estado social requiere de ellas para superar determinadas desigualdades ${ }^{22}$, dotando en consecuencia a los ciudadanos de un amplio margen de maniobra avalada por una estructura jurídica que garantiza su desenvolvimiento, tal y como consagra la Constitución española en su artículo 9.2: «Corresponde a los poderes públicos promover las condiciones para que la libertad y la igualdad del individuo y de los grupos en que se integra sean reales y efectivas; remover los obstáculos que impidan

${ }^{19}$ Ibídem, pág. 15.

${ }^{20}$ Ibídem, pág. 15.

${ }^{21}$ Dice Antonio Cassese que «en el fundamental principio de no discriminación que permea en toda la temática de los derechos humanos, dicho principio termina necesariamente por incidir sobre las normas tradicionales, que ya no pueden consentir distinciones (de raza, religión, sexo, origen nacional o social) que anteriormente eran en cierta medida admisibles». CASSESE, Antonio, Los derechos humanos en el mundo contemporáneo, Ariel, Barcelona, 1991, pág. 238.

${ }^{22}$ Cossio Diáz, José Ramón, Estado Social y Derechos de Prestación, Centro de Estudios Constitucionales, Madrid, 1989, pág. 36. 
o dificulten su plenitud y facilitar la participación de todos los ciudadanos en la vida política, económica, cultural y social».

Con la consagración por parte de la Constitución española del derecho a la igualdad parece que en un principio no se pudiera plantear ninguna duda en lo que concierne a su correcta aplicación. Cuestión que ha planteado un acalorado debate puesto, que lejos e independientemente que la aplicación desigualitaria tenga su fundamento en la palpable desigualdad existente (principalmente por la condición de no nacional, limitaciones de carácter político), muchas voces se levantan reclamando un trato estrictamente igualitario. Reivindicaciones que en muchos casos se canalizan en búsqueda de una solución ante los órganos judiciales en defensa de las constantes desigualdades existentes, no sólo en lo que respecta a discriminaciones por razón de sexo, religión, etc., sino también y especialmente por el tan creciente aumento de la población inmigrante de los años pasados que demanda un trato igualitario en todas las facetas de su vida. La vigente Ley de Extranjería, en lo que hace referencia a tratar de forma igual a los que están en condiciones de igualdad, identifica para dar un tratamiento semejante a los extranjeros que residan o estén legalmente en España, reconociéndoles una serie de derechos y libertades, intentando alcanzar el fin que tiene marcado la igualdad que «consiste en concretar los criterios materiales para llevar a cabo el valor de solidaridad, en crear las condiciones materiales para una libertad posible para todos, y en contribuir a la seguridad con la satisfacción de necesidades a quien no puede hacerlo por su propio esfuerzo» ${ }^{23}$.

Si se alcanzaran esos fines, la igualdad sería una realidad tangible mediante la cual se desarrollaría en plenitud el valor de dignidad, y recobraría fuerza el mencionado concepto de ciudadanía universal para reconocer la condición de ser humano y operar como fundamento para el levantamiento de prohibiciones o limitaciones de carácter estatal. Llegando el ser humano en estas condiciones a un pleno desarrollo de su personalidad, sin más intervención en su libre decisión que las estrictamente necesarias para orientarle en sus planes de vida, de tal forma que un individuo (inmigrante) que decida ejercer el derecho a la libertad de movimiento tenga aseguradas unas mínimas garantías. Sobre esta fundamentación se asienta la necesaria e íntima relación existente entre la dignidad y la solidaridad, llegando incluso, en ocasiones, a ser considerados valores complementarios el uno del otro, como de hecho ocurre en los casos en los que la solidaridad es

${ }^{23}$ En las palabras de Peces-Barba se demuestra nuevamente la estrecha vinculación existente entre los valores que aquí analizamos, Curso de derechos fundamentales... cit., pág. 283. 
utilizada como medio para alcanzar los parámetros que marcan la dignidad del hombre.

Por esta vía la solidaridad aquí constituye el conducto para alcanzar el reconocimiento de los derechos humanos de estos sujetos que se encuentran en situación de inferioridad con respecto a sus semejantes ${ }^{24}$. Por medio de la solidaridad, estos individuos que se encuentran mermados en sus derechos, alcanzan el nivel óptimo que marca la dignidad, adquiriendo su condición como ser humano que vive en sociedad, ya que es impensable la consideración del hombre como ser que vive en individualidad absoluta, sin relacionarse con los demás, porque va en contra de su propia naturaleza. Naturaleza que le incita a relacionarse con sus semejantes no sólo porque sea una opción más entre otras a elegir, sino porque nos referimos a una característica tan innata al individuo como necesaria, porque «en algún aspecto la solidaridad se le ofrece al individuo más que como una posibilidad de elegir a partir de su condición moral como una necesidad radical, al menos sí quiere poner a buen recaudo sus bienes más preciados» ${ }^{25}$. Es así como se ha podido decir que no hay contradicción entre el estado de naturaleza y el estado de sociedad, sino que el estado de naturaleza es precisamente el estado de sociedad.

En consecuencia, es una realidad afirmar que el ser humano es un ser sociable y caracterizado por ese elemento que marca la sociabilidad. Es, precisamente, la solidaridad la que lleva aparejada la idea de actuación en sociedad, que la convierte en el paradigma de lo que se conoce como dignidad social. A su vez se constituye paradójicamente en el estandarte de los flujos migratorios y como fin último que les garantice a los recién llegados una forma de vida digna en el país receptor. A este respecto Salvador Vergés apunta que «la dignidad del hombre va adquiriendo perfiles cada vez más definidos, a raíz de la promoción solidaria. En el fondo responde a la propia condición del hombre, que no es un ser solitario, sino en comunión con los demás, de suerte que la solidaridad es una secuela de la dignidad social de la

\footnotetext{
${ }^{24}$ Véase en este sentido el trabajo realizado sobre la solidaridad cuando se plantea si la solidaridad puede ser considerada como un derecho fundamental: «Contestación a la que se responde positivamente, considerando el derecho a la solidaridad como la otra cara de la obligación universal de los seres humanos de permitir que todos sus semejantes sean más libres, tanto en la posibilidad de disfrutar de los derechos civiles, políticos y sociales, como en la posibilidad de formar por sí mismos sus voluntades individuales», PÉREz GonZÁLEZ, David. E., «Solidaridad y Globalización», en AA. VV., Revista de la Facultad de Ciencias Jurídicas, n. ${ }^{\circ}$ 7, Universidad de Las Palmas de Gran Canaria, 2002, pág. 166.

${ }^{25}$ ARa Pinilla, Ignacio, Las transformaciones de los derechos humanos, Tecnos, Madrid, 1990, pág. 157.
} 
persona ${ }^{26}$. El hombre, como hemos dicho, es un ser que tiende a vivir en sociedad relacionándose con los demás. De ahí que la solidaridad se utilice como instrumento para alcanzar este objetivo y se reconozca con carácter universal un derecho, el cual no debe tener ningún condicionamiento fronterizo de las naciones, sino al contrario una magnitud internacional y con idéntica consideración en cualquier Estado. Nos referimos al derecho a la convivencia, y en concreto, al derecho que tienen los inmigrantes como miembros de la sociedad internacional que gozan de la condición de ciudadano universal de convivir de convivir en condiciones de igualdad con otros semejantes. La consagración de este derecho a la convivencia deja patente la importancia de la solidaridad como mecanismo impulsor de las relaciones internacionales, y también como instrumento verdaderamente útil para alcanzar un reconocimiento social del hombre a nivel internacional.

Ciertamente en los tiempos que corren, donde las tan acuciantes divergencias que existen entre los diferentes territorios del planeta inspiran todavía más la necesidad de procurar un nuevo rumbo de la dignidad. Este distinto perfil debe promover una cierta armonización en la configuración básica del ser humano «ya que el problema del reconocimiento del hombre tiene un alcance mundial, que exige el nuevo planteamiento de la solidaridad entre las naciones ${ }^{27}$. Esto, lógicamente, va a implicar la necesaria comunicación entre Estados y un reforzamiento del concepto de ciudadano universal que «representa la configuración de la dignidad del hombre contemporáneo, pues éste se intercomunica continuamente con todos los demás hombres del mundo ${ }^{28}$. Por este motivo no podemos encuadrar al ser humano dentro de los límites fronterizos de su nación, sino que muy al contrario, cada vez más se enfatiza en las relaciones internacionales entre individuos de diferentes lugares. Véase en este sentido, el fenómeno conocido como globalización, que en su acepción más amplia conlleva una interconexión de todos los pueblos del mundo en su afán de pretender, sobre todo desde el punto de mira de la globalización social, alcanzar la justicia.

El establecimiento del concepto de derecho a la convivencia y el desarrollo de la solidaridad internacional se hace mucho más acuciante cuando estamos en presencia de países que tienen entre sí unas marcadas diferencias en su desarrollo. Y es que, precisamente por encontrarnos, hoy en día, con estas variantes tan abismales en el de-

\footnotetext{
${ }^{26}$ Vergés Ramírez, Salvador, Derechos humanos: Fundamentación, cit., pág. 93.

${ }^{27}$ Ibidem, pág. 152.

${ }^{28}$ Ibídem, pág. 153.
} 
sarrollo de un Estado con respecto al otro, es por lo que se debe incentivar más esa idea de cooperación solidaria y de avance en el camino en el que se vayan difuminando las diferencias. De tal forma que cualquier ser humano, independientemente de donde haya nacido o de donde desee vivir, alcance el reconocimiento que es sustancial con el valor que representa la dignidad ${ }^{29}$.

\section{LOS POSTULADOS DEL UNIVERSO GLOBAL}

\section{IV.1. Planteamiento}

En un tema tan polémico como es la globalización no pueden faltar desde luego posturas contrapuestas sobre su defensa y ataque. Los argumentos que cada uno de los agentes intervinientes en este fenómeno aportan son múltiples, pero nosotros trataremos de exponer los más relevantes, acudiendo, naturalmente, para ello a algunas de las diferentes opiniones que, sobre el mismo, se han vertido.

En un primer análisis, podríamos llegar a la conclusión que los dos lados extremos, tanto a favor como en contra, son defendibles. Todo dependerá de la perspectiva que adopte el agente que los examina. A su vez, también, las posturas intermedias resultan defendibles, ya que, al adoptar una posición menos tajante que las anteriores, emergen aspectos y matices cuyos beneficios, unas veces, y perjuicios en otras, son demostrables.

Posturas éstas que no sorprenden de un fenómeno de tal magnitud como es éste, pues el número de elementos, facetas y aspectos en los que repercute se hace indeterminable en extensión numérica.

\section{IV.2. Posturas a favor}

El hecho que el mundo esté en mayor conexión, motivado por la globalización, donde los acontecimientos de un determinado lugar repercuten en otro diferente, en principio parece que puede ser ventajoso, por potenciar de esta manera la solidaridad internacional. De tal manera que, para solucionar los problemas que determinados países tienen, y los cuales no pueden subsanar por sí solos, como es la po-

${ }^{29}$ Teoría, ésta, que es vista con cierto escepticismo por Salvador Vergés porque según su criterio «media, en efecto, un tal abismo entre los países desarrollados y los subdesarrollados, que hace inviable la solidaridad de unos para con los otros», ibidem, pág. 154. 
breza del tercer mundo, sean ayudados por toda la comunidad internacional. Esta es una cuestión de tal relevancia, que en la mayoría de las ocasiones se les escapa de las manos a estos países, que necesitan irremediablemente apoyo de terceros Estados ${ }^{30}$.

Muchas veces el camino utilizado es la petición de préstamos lo que crea una deuda externa ${ }^{31}$, la cual no pueden asumir, produciéndose perjuicios importantes imposibles de reparar por los Estados deudores por sí solos, teniendo que acudir irremediablemente a pedir la condonación de la deuda ${ }^{32}$.

Otro de los argumentos con los que contamos para defender las ventajas de la globalización, es que esta mayor conexión del mundo de la que venimos hablando conlleva también el aumento de los flujos migratorios que en Europa y, concretamente, en España son necesarios por la baja natalidad existente, amortiguada por la población inmigrante. Pero eso sí, como se expone en este trabajo, la inmigración no implica siempre y en todos los casos ventajas puesto que en muchas ocasiones acarrea importantes problemas con difícil solución.

Entre los defensores de la globalización encontramos los que opinan que el libre comercio es un aliado de los trabajadores porque genera riqueza, y si cada país puede comerciar con libertad, entonces, la economía mundial crecerá, facilitando el intercambio de nuevas tec-

${ }^{30}$ La interconexión a nivel internacional viene de la mano de que «esta mundialización es el hecho de que la comunicación entre las diversas partes del mundo es cada vez más rápida y fácil y de que, en consecuencia, hay más influencia recíproca entre las partes», Escamilla Castillo, Manuel, «Demos y Democracia», en Anuario de Filosofía del Derecho, Tomo XXIII, 2006, pág. 269.

${ }^{31}$ Véase lo que se entiende por deuda externa: «un país necesita tener medios de pago internacionales (divisas) para afrontar diversos tipos de obligaciones: a) el pago de los insumos importados necesarios para sus industrias locales; b) el pago de la importación de artículos de consumo (alimentos, productos manofacturados, etc.); c) el pago de las regalías que se deben a empresas extranjeras por la utilización de patentes y marcas; d) el pago de intereses y amortizaciones de préstamos contraídos en el extranjero; e) la remisión al exterior de los beneficios obtenidos en el país por expresas extranjeras y f) por último, aunque no por ello menos importante, el pago de armamentos adquiridos en el extranjero», Teitelbaum, Alejandro, "La Deuda Externa», en Revista Glocal, Política, Economía, Cultura, Sociedad, año 1, n. ${ }^{\circ}$ 6, Rodma Comunicaciones, 2000, pág. 1.

${ }^{32}$ A modo de aclaración, vemos cómo «dicho problema consiste en que la deuda de dichos países crece año tras año de manera desmesurada, que estos países están dentro de una espiral integral en la que deben contraer nuevos préstamos para pagar los intereses de los préstamos anteriores (ya casi no se encara la posibilidad de amortizar parte del capital adeudado) y que sus obligaciones internacionales crecen mucho más rápidamente que la capacidad de pago generada por su actividad económica interna y por sus intercambios internacionales, todo lo cual apareja consecuencias sociales sumamente graves», Ibidem, pág. 2. 
nologías y mejorando las condiciones de vida de todos los habitantes del planeta. La mayor apertura económica internacional se traducirá en un impulso del crecimiento económico. Pero, como cabe la posibilidad de que ese crecimiento no afecte a todos por igual, sino que las economías más prosperas salgan más beneficiadas que las más pobres, es por lo que es necesario que se introduzcan mecanismos correctores que disminuyan los desequilibrios de las diferentes economías internacionales.

Uno de estos mecanismos puede ser el impulso de las economías menos favorecidas, de tal manera que la hagan mucho más competitiva. Un ejemplo que puede servir de orientación es lo que se ha hecho en la Unión Europea mediante una política activa que pretende la corrección de disparidades entre las diferentes regiones que la forman. Al establecer la libertad de mercado, eso sí controlando la implantación de monopolios, la competencia se convierte en el eje central para el establecimiento de precios y calidad, lo que sin duda repercute beneficiosamente en el consumidor. Al respecto, al argumentar la defensa de este fenómeno se observa cómo «los apologistas de la globalización han presentado sus puntos de vista como un paradigma y como un dogma, ya que no hay otro camino para alcanzar el mayor nivel de riqueza más que a través del paradigma neoliberal, supuestamente, de laissez faire (de dejar hacer). Para eso tratan de apoyarse en teorías económicas como si fuesen postulados indisputables, al afirmar que es un paradigma científico» ${ }^{33}$.

Las nuevas tecnologías, Internet y el comercio electrónico, se configuran como elementos impulsores de un mercado donde la rapidez y la eficacia sean sus guías de actuación. El comercio electrónico abre las ventanas a todo el mundo, para que todos los países puedan vender sus productos en todo el planeta con rapidez y bajo coste de inversión, lo que hará a los procesos de producción más eficaces y rentables. En este sentido, se ha pronunciado el Fondo Monetario Internacional, afirmando que «la globalización ofrece grandes oportunidades de alcanzar un desarrollo verdaderamente mundial, pero no está avanzando de manera uniforme. Algunos países se están integrando a la economía mundial con mayor rapidez que otros. En los países que han logrado integrarse, el crecimiento económico es más rápido y la pobreza disminuye. (...) Gracias a la globalización, es posible beneficiarse de mercados cada vez más vastos en todo el mundo

\footnotetext{
${ }^{33}$ Regil CAStilla, Álvaro de, «Globalizar la riqueza: justicia social en la era de la globalización, La globalización: sus estrategias y dilemas», en Revista Nexos Virtual, 2001, en:

http://www.nexos.com.mx/internos/foros/globalizacion/alvaro1.asp, pág. 4.
} 
y tener mayor acceso a los flujos de capital y a la tecnología, y beneficiarse de importaciones más baratas y mercados de explotación más amplios. Pero los mercados no garantizan necesariamente que la mayor eficiencia beneficiará a todos. (...) Todos los países deberían tener como objetivo reducir la pobreza. La comunidad internacional debería esforzarse -fortaleciendo el sistema financiero internacional a través del comercio exterior y de la asistencia- por ayudar a los países más pobres a integrarse en la economía mundial, a acelerar su crecimiento económico y a reducir la pobreza. Esta es la mejor forma de garantizar que todas las personas de todos los países se beneficien de la globalización ${ }^{34}$.

En efecto, la diferente implantación de los nuevos sistemas económicos a nivel mundial entre los países es una realidad que incide en uno de los vértices esenciales del proceso globalizador, la intercomunicación internacional entre diferentes mercados. Lo que implica, efectivamente, el aumento de las diferencias entre Estados, sobre todo en los que el nivel de desarrollo está muy por debajo de la media internacional. Es un punto que no puede pasar desapercibido en el análisis de la globalización, porque de igual manera que ofrece posibilidades de mejorar el nivel de desarrollo de determinados países, puede también, ser el motivo por el que estas naciones incrementen el nivel de pobreza en el que se encuentran inmersas ${ }^{35}$.

\section{IV.3. Posturas en contra}

Las posturas contrarias están encabezadas por los movimientos antiglobalización que tienen marcado como uno de sus principales objetivos frenar el poder que las grandes compañías multinacionales puedan adquirir. Poder mediante el cual releguen a un segundo plano a la persona como tal, poniendo énfasis en la competitividad y la supremacía del dinero. Destacamos sobre esta línea el Movimiento de Resistencia Global que empezó a gestarse en el año 1993 como corriente de protesta mundial que reúne grupos de diferentes países y organizaciones internacionales que tienen como fin último el rechazo

${ }^{34}$ Fondo Monetario Internacional, La globalización: ¿Amenaza u oportunidad?, Estudios Temáticos, 2000, en:

http://www.imf.org/external/np/exr/ib/2000/esl/041200s.htm, págs. 1-12.

${ }_{35}$ Al respecto consultar, Pisarello Prados, Gerardo, «Derechos sociales, democracia e inmigración en el constitucionalismo español: del originalismo a una interpretación sistemática y evolutiva», en AA. VV., María José Añón (editora), La universalidad de los derechos: el reto de la inmigración, Tirant lo Blanch, Valencia, 2004, págs. 78 y ss. 
al capitalismo y a las doctrinas y principios que marca el modelo neoliberal. De entre sus reclamaciones destaca la petición de la condonación de la deuda externa de los países pobres y la protección del medio ambiente. Desean una sociedad más justa y un reparto equitativo de la riqueza, potenciando la democratización y limitando el poder de las grandes compañías multinacionales como impulsores de la sociedad mundial, puesto que sus objetivos son únicamente económicos, dejando al margen otros que para el ser humano tienen una relevancia mayor, como es la efectiva defensa de los derechos humanos ${ }^{36}$.

Aquí el rechazo a la globalización encuentra su fundamento en la estricta orientación económica del fenómeno, puesto que una globalización en la que únicamente se tenga como guía de conducta a seguir las implicaciones económicas del planeta obliga a tomar una actitud absolutamente partidista en la que los intereses económicos sean la cúpula del proceso, en detrimento de otros intereses más importantes para el ser humano como son por poner un ejemplo los relativos a la salvaguarda y realización de sus derechos sociales.

También el fenómeno de la globalización ha sido criticado por lo que puede implicar de perdida de la identidad de los pueblos, motivado por esa apertura mundial, ya que al estar todo tan entrelazado, las culturas regionales pueden perder la autenticidad que las configura como tales, asumiendo manifestaciones de otra cultura que desvirtúe su originalidad. Al respecto, incluimos una opinión que, desde luego, no deja en buen lugar este fenómeno al declarar que «la globalización tiene también un aspecto ofensivo/defensivo. Es un proceso que más que unir, divide, y geoestratégicamente viene a depositarse sobre una desgarrada lucha por superar una profunda crisis que se viene arrastrando por la última década en medio de una competencia cada vez más feroz por el reparto de ganancias y de territorios» ${ }^{37}$.

${ }^{36}$ Sobre la repercusión negativa que produce este fenómeno se ha manifestado Regil Castilla, al afirmar que «la oposición a la globalización se centra en dos factores principales. Primero, es crecientemente evidente que el paradigma no ha cumplido con las expectativas ofrecidas por quienes lo promueven y está generando tremendas iniquidades tanto en los países ricos como en aquellos en desarrollo. Además de que hay una creciente abundancia de estudios muy serios que dan testimonio de estas tendencias, los simples indicadores económicos de muchos países ricos, empezando por Estados Unidos e Inglaterra, dan clara fe del deterioro social; no se diga de los resultados en los países del tercer mundo donde esto es drásticamente evidente. En consecuencia, está ahora claro que el paradigma neoliberal es inherentemente injusto, porque ha sido pensado en beneficio exclusivo de quienes lo gestaron: los centros de poder económico y político». REgIL CASTILla, Álvaro de, "Globalizar la riqueza: justicia social en la era de la...» cit., pág. 7.

${ }^{37}$ García Morales, Federico, Globalización: definiciones, ideología y realidades, 2001, en: http://www.rcci.net/globalizacion/llega/fg096.htm, pág. 6. 
Habría que añadir como elemento a valorar en este análisis de los postulados no favorecedores del fenómeno el aumento de los movimientos migratorios. Los trasvases de personas de un lugar a otro pueden provocar en la sociedad de acogida que en cierta manera la globalización genere que determinados territorios puedan perder su identidad. Esto se ve incrementado cuando determinadas personas, al trasladarse a un lugar diferente al de su origen, deben integrarse en una nueva sociedad, hecho que acarrea, en la mayoría de las ocasiones, la pérdida de la cultura propia en favor de los hábitos de la sociedad receptora. Eso sí salvo que tenga implantado un buen sistema en el que el multiculturalismo esté garantizado. Planteamiento que o todas luces goza de una considerable dosis de utopía.

Otro de los argumentos en contra, es el que afirma que «la oposición a la globalización no está basada en la internacionalización de la economía, sino en los efectos que ésta produce sobre la pérdida de la autonomía en las políticas económicas de los gobiernos nacionales o sobre el desmantelamiento del Estado de Bienestar. (...) En franca oposición a esta perspectiva, D. Ghai y C. Hewit (1994) argumentan que los cambios en la cultura acompañan una desintegración social, hecho que está ocurriendo bajo un contexto de un colapso económico global. Afirman estos autores que la crisis estructural de la sociedad capitalista está produciendo nuevas formas de organización y control social. En este caso, la globalización afectaría a distintas formaciones culturales sin que estas posean la capacidad para deslocalizar el proceso de su eje director, ya que desempeñarían un papel pasivo en la reestructuración de los mecanismos de poder» ${ }^{38}$.

Esta postura es apuntada cuando se habla del Estado de bienestar, puesto que el proceso globalizador conlleva un profundo cambio en las políticas sociales. En opinión de Giddens ${ }^{39}$, tal y como lo tenemos configurado hoy, el Estado de Bienestar, no se puede considerar como un instrumento capaz de dar respuesta a los grandes cambios y a la nueva situación social que se ha producido en los países desarrollados y que afecta a un variadísimo cúmulo de aspectos, como es por ejemplo, el trabajo. El Estado de bienestar pasa a adoptar una posición

${ }^{38}$ Algaba Calvo, Antonio, Azevedo Da Silva, Clecio, «La aproximación de la geografía a la globalización: análisis bibliográfico de los estudios reseñados en Geographical Abstracts entre 1992 y 1996», en Biblio 3W. Revista Bibliográfica de Geografía y Ciencias Sociales, Universidad de Barcelona, n. ${ }^{\circ}$ 51, 13 de octubre de 1997, págs. 5-8, nombrando a GHAI, D., HewITT, C., Globalization and social integration: patterns and processes. Occasional paper United Nations research Institute for Social Development, 2, 1994.

${ }^{39}$ Giddens, Anthony, Más allá de la izquierda y de la derecha. El futuro de las políticas radicales, Cátedra, Madrid, 1996, págs. 139-155. 
residual mediante la cual y, en la mayoría de las ocasiones, prepondera la intervención de los agentes externos a la esfera pública, relegando a estas políticas de bienestar a la satisfacción de necesidades en el caso que no sean cubiertas por otra vía, e incluso adoptando el Estado una postura de mero controlador mediante el establecimiento de las directrices que han de regir las relaciones económicas que se sucedan. Eso sí, directrices de obligatorio cumplimiento, puesto que el no acatamiento de las mismas acarreará las correspondientes consecuencias negativas. Ya que una cosa es que el ente público adopte una posición de menor relevancia económica y otra muy diferente que pierda su fuerza impositiva, aunque a la larga puede que también la pierda.

De todos estos argumentos que se apuntan sobre las desventajas que la globalización produce, es necesario destacar la labor de las ONGs que como Anmistía Internacional desafían a la globalización mediante la repulsa de una globalización estrictamente económica en la que se dejen de lado cuestiones tan importantes como es la defensa de los derechos humanos ${ }^{40}$, reclamando, entonces, una globalización integral que aglutine no sólo el aspecto económico sino, también, el social, político, etc.

\section{LA REDEFINICIÓN DEL SENTIDO DE LA GLOBALIZACIÓN}

Los movimientos migratorios, ya se ha apuntado, tienen multiplicidad de causas, pero es importante mencionar entre ellas la presión económica que provoca movimientos de millones de personas que buscan mejores condiciones de vida. Por medio de la globalización, la apertura de fronteras de los diferentes países se hace cada vez más

${ }^{40}$ Para Anmistía Internacional «la agenda de las organizaciones de derechos humanos se había dirigido con toda pasión a la defensa de los derechos civiles y políticos, pasando por alto el hecho de que la tercera parte de los habitantes en países en desarrollo son esclavos de una pobreza tan ingente que les priva de sus derechos fundamentales a una vida digna. (...) los nuevos retos en materia de derechos humanos derivados de la globalización han alentado a Anmistía a asumir nuevas áreas de trabajo, como los derechos socioeconómicos. (...) Para Anmistía la globalización ha ido acompañada de la deuda y la pobreza. Más de 80 países tenían en el año 2000 una renta per cápita inferior a la de 1990. La liberalización, la privatización y el desmantelamiento de los servicios de asistencia social han llevado a un incremento de las desigualdades en muchos países. En muchas zonas del mundo a aumentado la corrupción, y la inseguridad personal, social y política se ha extendido. La consecuencia previsible y casi inevitable de este aumento de la pobreza ha sido a escalada paralela de las violaciones de todos los derechos humanos», El País 19 de agosto de 2001. 
intensa, de tal forma que las políticas globales para la emigración requieren una actuación coordinada en la lucha contra el subdesarrollo ${ }^{41}$.

En este sentido, términos hasta entonces consagrados a campos específicos son retomados para su adaptación con el nuevo entorno mundial. Se puede afirmar, utilizando palabras de Javier de Lucas que «la categoría de ciudadanía y su vinculación a la nacionalidad, así como su configuración progresivamente en términos de ciudadanía excluyente-que no inclusiva- es la clave de un proceso, al que no son ajenos, claro está, los fenómenos de la globalización del mercado y de cambio en los flujos migratorios ${ }^{42}$.

Por tanto, vemos cómo la globalización, en ningún caso, puede ser analizada solamente desde un punto de vista económico, ya que el término admite muchos matices. Porque lógico es que cuando nos referimos únicamente al aspecto económico queden fuera los países en los que el nivel de desarrollo económico es bajo, pero no por este motivo van a estar al margen del proceso globalizante, sin afectarles. Al contrario, ningún país está exento de las consecuencias del fenómeno, por eso es del todo necesario que la globalización no afecte exclusivamente a aspectos económicos sino a todos los demás.

Desde la exclusiva faceta económica, los países más pobres no tienen capacidad productiva ni tecnológica para participar en ese mercado global en condiciones de igualdad con los países desarrollados, y no por eso no se van a quedar exentos de la dinámica mundial $^{43}$. Razón ésta, más que suficiente para afirmar que más que globalizar el capital es necesario crear un marco jurídico vinculante que garantice el cumplimiento efectivo de los derechos humanos en todo el planeta y se establezca un sistema democrático que ampare a toda

${ }^{41}$ Sobre las repercusiones jurídicas que origina el proceso globalizador consultar LAPORTA, Francisco, «Globalización e imperio de la ley. Algunas dudas westfalianas», en Anales de la Cátedra Francisco Suárez, n. ${ }^{\circ}$ 39, 2005, págs. 243 y ss; más reciente El imperio de la ley: una visión actual, Trota, Madrid, 2007; también del mismo autor puede consultarse, "Imperio de la ley: reflexiones sobre un punto de partida de Elías Díaz», en Doxa, 1994.

${ }^{42}$ LuCAS, Javier de, «Por qué son relevantes las reivindicaciones jurídico-políticas de las minorías", en Cuadernos de Derecho Judicial, Derechos de las minorías en una sociedad multicultural, Consejo General del Poder Judicial, Madrid, 1999, pág. 274.

${ }^{43}$ Sobre la diferenciación económica que existe entre los diferentes países del mundo se ha manifestado Servitje, afirmando que «la acentuación de un fenómeno que puede tener proporciones alarmantes y que es la migración galopante de los habitantes de los países pobres hacia los países más ricos», SERviTJE, Lorenzo, «La globalización y sus consecuencias en la sociedad», Conferencia dictada en el VII Congreso UNIAPAC Latinoamericano, Canela, Río Grande do Sul, Brasil, en Revista Entorno, México, enero de 1998, pág. 30. 
la humanidad con el reconocimiento jurídico de un Estado de Derecho, en el que quede consagrado, también, una globalización política y social ${ }^{44}$.

$\mathrm{Al}$ respecto Barretto confirma que «en este momento estamos viviendo un proceso de globalización que, por algunas razones favorece a las migraciones, al tiempo que amplía el abanico de sus motivaciones y, por ende, los grupos sociales que la practican. Vemos así que muchas personas aun teniendo satisfechas sus condiciones elementales de vida apelan a la emigración para conseguir su lugar en el mercado de consumo. La globalización de la economía hace que las personas se desplacen al sabor de las oportunidades ofrecidas por el capital internacional, y el avance tecnológico en el área de las comunicaciones hace posible desplazamientos a grandes distancias, manteniendo un contacto impensable hasta hace dos décadas» ${ }^{45}$

Por lo tanto, se puede afirmar sin lugar a dudas que la migración internacional es una realidad actual creciente por los impulsos de la globalización. De todas maneras, se observa un cierto descuido a la hora de tratar ambos fenómenos en su conjunto, pues muchos de los acuerdos de liberación se limitan a la libre circulación de capital, mercancías y de los agentes del capital y excluyen la movilidad de la mano de obra, esencial para consumar esos acuerdos.

El vigente movimiento de personas de un lugar a otro implica, indirectamente, aunque sin lugar a dudas, la atribución a esos individuos de una legitimación específica para exigir el reconocimiento sus derechos. De tal manera, que «por eso hoy en buena medida, los nuevos inmigrantes, más aun que las minorías e incluso las poblaciones indígenas, son, como se ha apuntado desde muy diferentes posiciones, quienes representan ese nuevo sujeto universal, ese nuevo grupo de desposeídos de todo salvo de su condición de seres humanos, que les permite convertirse en agentes de la lucha por vencer frente a la

${ }^{44} \mathrm{Al}$ respecto especifica Maspero que «culmina la independencia política como una nueva forma de independencia nacional, social y cultural, no cerrada sobre la geografía de la región sino abierta a todo el mundo. Es la mejor respuesta y propuesta para una inserción activa, creativa con nuestra propia identidad y determinante dentro de un inevitable proceso de interdependencia globalizante, pero apostando a un orden mundial distinto, no sólo más libre y democrático, sino más justo, más solidario, que culmine la unidad de la familia humana en un ambiente de confraternidad», MASPERo, Emilio, Mundialización, globalización y la patria grande latinoamericana, Conferencia en la Universidad de los Trabajadores de América Latina en San Antonio de los Altos, el 6 de octubre de 2001, pág. 5.

${ }^{45}$ Barretto, Margarita, "Ciudadanía, globalización y migraciones», en Revista Naya. La Colección. Ciudad Virtual de Antropología y Arqueología, junio de 2001, pág. 4. 
penúltima barrera a la que se enfrenta el viejo ideal emancipador de los derechos humanos ${ }^{46}$. Aunque, desde luego, tras esa afirmación es necesario hacer una matización, puesto que la legitimación de la que aquí se habla, no cabe duda, es una legitimación para exigir el reconocimiento de los derechos humanos para todos los individuos. Pero es una legitimación únicamente teórica, pues las limitaciones que se imponen a los sujetos son una constatación jurídica en las diferentes legislaciones de los Estados. Pero no por eso se niega esa legitimación de la que hablamos. Al contrario, la titularidad de los derechos humanos viene ya marcada en su propia configuración, lo que nos permite asegurar que la problemática que lleva a migrar es multidimensional, y que actualmente el desempleo ocupa un lugar destacado, afectando no sólo a los migrantes y su repercusión en el reconocimiento de derechos sino que también conlleva importantes consecuencias en las relaciones económicas y sociales de los países involucrados. Por ello se hace necesario pactar reglas internacionales para enfrentar el problema tanto en la defensa de los derechos humanos, como para regular la circulación de la mano de obra.

Éste es el espíritu que aparece reflejado en la Declaración sobre el Progreso y el Desarrollo de lo Social, proclamada por la Asamblea General de Naciones Unidas en su resolución 2542 (XXIV), de 11 de diciembre de 1969, que en su artículo 19 apartado c) dice que para el logro de los objetivos marcados se establecerán «la adopción de medidas y la prestación de servicios de bienestar social a los trabajadores migrantes y a sus familias, de conformidad con lo dispuesto en el Convenio n. ${ }^{\circ} 97$ de la Organización Internacional del Trabajo y en otros instrumentos internacionales relativos a los trabajadores migrantes». Aquí se habla de la necesidad de que se formulen reglas internacionales para la regulación uniforme de los flujos migratorios, lo cual no quiere decir que sólo los Estados dentro de sus competencias y soberanía establezcan todos los medios que crean convenientes para aplicarlos a sus concretos y específicos problemas, porque «las fronteras nacionales no son barreras para la migración transnacional sino mecanismos funcionales para la provisión de trabajo a una escala global y para la reproducción del sistema» ${ }^{47}$.

Además, en los mecanismos hasta ahora vigentes se hace imprescindible una reorganización de los sistemas en los que estén encua-

${ }^{46}$ LuCAS, Javier de, "Por qué son relevantes las reivindicaciones jurídico-políticas...» cit., pág. 293.

${ }^{47}$ RoBINSON, Willian I., «La globalización capitalista y la transnacionalización del Estado", trabajo presentado al Taller Trasatlántico sobre Materialismo Histórico y la Globalización, Universidad de Warwick, abril de 1998, pág. 7. 
drados los nuevos sujetos que aparecen legitimados para exigir el cumplimiento de los nuevos mandatos que la nueva situación mundial exige. Idea confirmada por Javier de Lucas al decir que «eso explica en mi opinión el carácter paradigmático de las reivindicaciones planteadas por las minorías, por los pueblos indígenas, por esos nuevos extranjeros que son los protagonistas de los nuevos flujos de la inmigración, porque nuestra respuesta a esas reivindicaciones no puede seguir siendo la alegación reiterativa y mecánica de los cauces habituales ${ }^{48}$.

Esta necesidad de adaptación de la nueva situación con los derechos humanos se desprende de las Resoluciones de la Comisión de Derechos Humanos 2000/4 y 2001/5, sobre El racismo, la discriminación racial, la xenofobia y las formas conexas de intolerancias, de las Naciones Unidas, en sus respectivas sesiones el 17 de abril de 2000 y el 18 de abril de 2001, la Comisión reconoce que está «profundamente preocupada porque, pese a los esfuerzos realizados, las formas contemporáneas de racismo, discriminación racial, todas las formas de discriminación, en particular contra los negros, árabes y musulmanes, la xenofobia, la negrofobia, el antisemitismo y las formas conexas de intolerancia persisten, incluso cobran incremento sin cesar, revistiendo continuamente nuevas formas, entre ellas la tendencia a establecer políticas basadas en la superioridad o el exclusivismo de tipo racial, religioso, étnico cultural y nacional (...). Pide a todos los Estados que examinen y, cuanto sea necesario, revisen sus políticas de inmigración incompatibles con los instrumentos y las normas internacionales relativos a los derechos humanos con miras a eliminar todas las medidas y prácticas discriminatorias con respecto a los inmigrantes».

\section{A MODO DE CONCLUSIÓN}

En los últimos tiempos se han sucedido una serie de cambios que han supuesto una nueva concepción del contexto mundial. Han caído barreras, durante largo tiempo vigentes, y sin embargo han aparecido otras nuevas. Como elemento directamente relacionado con la pobreza y los niveles de desarrollo se encuentra el fenómeno de la inmigración, que actúa a caballo de las mutaciones del planeta.

${ }^{48}$ Lucas, Javier de, "Por qué son relevantes las reivindicaciones jurídico-políticas...», cit., pág. 292. 
Las crecientes interrelaciones de todo orden entre las diferentes regiones del globo y la cada vez más intensa globalización, no han impedido que las diferencias de desarrollo, de avances democráticos, de crecimiento y variaciones demográficas y de nivel de vida sean cada vez mayores. En este sentido la emigración juega un papel preponderante en la esfera mundial, puesto que los cambios que propone la globalización también conllevan el aumento de movimientos de individuos, apelando a la libertad de circulación de personas como efecto íntimamente ligado a la apertura mundial de los mercados. En este fenómeno, todas estas cuestiones, al igual que las políticas de inmigración han de ser multidisciplinares e incluir diversas facetas en el desarrollo de sus acciones con el fin de alcanzar un mayor consenso que de satisfacción a las pretensiones de todos los agentes implicados.

Desde el punto de vista social, el traslado de ingentes cantidades de personas de un lugar a otro implica tomar conciencia y prevenir los efectos socioeconómicos indeseables, tanto en los países receptores como emisores, profundizando esfuerzos en la lucha contra las violaciones a los derechos humanos, como en especial se sucede cuando se produce el tráfico ilegal de inmigrantes, que exige establecer mecanismos eficaces de gestión y control, con políticas de codesarrollo, orientadas tanto al bienestar económico de los países emisores como a su estabilidad política y democrática.

En este sentido la globalización propone posturas contradictorias. Por un lado, con este nuevo proceso parece que las políticas del Estado de Bienestar han quedado obsoletas, entrando en crisis en las últimas décadas y siendo sustituidas por la ideología neoliberal que considera al mercado como el motor de la sociedad.

La globalización plantea, desde el punto de vista de sus consecuencias sobre la cultura y la identidad de los pueblos, unos efectos que tendrán una importancia no menor que sus consecuencias económicas. Así que la globalización en todas sus manifestaciones es un hecho incorporado a la forma de vida, que condiciona en gran medida todos los aspectos que afectan no sólo a las instituciones y organismos públicos que tienen que desarrollar unas políticas acordes con los nuevos tiempos sino también a los ciudadanos de a pie.

Asimismo, en la misma línea la inmigración se constituye como un factor estructural del mundo que hace que las sociedades dejen de ser lo que fueron y donde la básica distinción entre nacionales y extranjeros ya no es tan simple ni nos es válida, puesto que se entrelazan en su significación y contenido aspectos de índole superior a la 
que los Estados les puedan otorgar, forzando a que nociones ya comúnmente conocidas, como la soberanía, derechos nacionales, pluralidad cultural, solidaridad, integración, etc., sean traídas de nuevo a debate para darles una nueva orientación acorde con los fenómenos actuales.

El trato en condiciones de igualdad se enlaza necesariamente con la prohibición de la discriminación racial de las personas que, por muy diferente raza que tengan, tienen derecho a trasladarse a un lugar diferente al de su nacimiento, ejerciendo así el derecho a la emigración. Alegato éste que no nos puede llevar más que a corroborar que en su análisis teórico el principio de no discriminación debe ser disfrutado, también en este ámbito, por todo ser humano. Cuestión diferente es su hipotética materialización empírica en casos concretos que, lejos de seguir las secuencias lógicas que propugna su configuración teórica, en la praxis se apartan de los cánones establecidos, marcando sustanciales diferencias entre los hombres. Disertación ésta clarificadora para los movimientos migratorios porque sienta las bases sobre las que deben desarrollarse e inspirarse las normativas que hagan referencia directa o indirectamente a la igualdad como criterio base y principio regidor de todo comportamiento y regulación jurídica, debiendo de esta manera sustentar el espíritu jurídico de cualquier normativa nacional e internacional.

En materia de derechos humanos resulta a todas luces necesario recalcar el significado de la universalidad como estandarte para el reconocimiento de la dignidad humana, porque el término ciudadanía y el consecuente reconocimiento de unos derechos a un individuo que goza de esa consideración queda diluido en el entorno del mercado internacional, en el que las fronteras nacionales se difuminan por la inmersión del mercado y de todos sus agentes en una dimensión globalizada del mismo.

\section{BIBLIOGRAFÍA}

ALGABA CALVO, Antonio - AZEVEDO DA SILVA, Clecio, «La aproximación de la geografía a la globalización: análisis bibliográfico de los estudios reseñados en Geographical Abstracts entre 1992 y 1996», en Biblio 3W. Revista Bibliográfica de Geografía y Ciencias Sociales, Universidad de Barcelona, n. ${ }^{\circ}$ 51, 13 de octubre de 1997.

Anmistía Internacional, El País, 19 de agosto de 2001. 
ANSUÁTEGUI ROIG, Francisco J., «La relación entre los derechos fundamentales y el Estado de Derecho: dimensiones y consecuencias», en Anuario de Filosofía del Derecho, Tomo XXIII, 2006.

ARA PINILLA, Ignacio, Las transformaciones de los derechos humanos, Tecnos, Madrid, 1990.

ARA PINILLA, Ignacio, «El significado de la solidaridad como valor fundante de los derechos humanos", en A. de Julios Campuzano (editor), Dimensiones jurídicas de la globalización, Dykinson, Madrid, 2007.

BARRETTO, Margarita, «Ciudadanía, globalización y migraciones», en Revista Naya. La Colección. Ciudad Virtual de Antropología y Arqueología, junio de 2001.

BUERGENTHAL, Thomas, GROSSMAN, Claudio, NIKKEN, P., Manual Internacional de Derechos Humanos, Instituto Interamericano de Derechos Humanos, Editorial Jurídica Venezolana, Caracas, San José, 1990.

CASSESE, Antonio, Los derechos humanos en el mundo contemporáneo, Ariel, Barcelona, 1991.

COSSIO DIÁZ, José Ramón, Estado Social y Derechos de Prestación, Centro de Estudios Constitucionales, Madrid, 1989.

ESCAMILLA CASTILLO, Manuel, «Demos y Democracia», en Anuario de Filosofía del Derecho, Tomo XXIII, 2006.

FERNÁNDEZ GARCÍA, Eusebio, «Estado, sociedad civil y democracia», en AA. VV., Valores, derechos y Estado a finales del siglo XX, Dykinson, Madrid, 1996.

FERRAJOLI, Luigi, «Derechos fundamentales», en FERRAJOLI, L., El fundamento de los derechos fundamentales (edición de A. de Cabo y G. Pisarrello), Trota, Madrid, 2001.

FONDO MONETARIO INTERNACIONAL, La globalización: ¿Amenaza u oportunidad?, Estudios Temáticos, 2000, en:

http://www.imf.org/external/np/exr/ib/2000/esl/041200s.htm.

GARCÍA MORALES, Federico, Globalización: definiciones, ideología y realidades, 2001, en: http://www.rcci.net/globalizacion/llega/fg096. htm.

GARCÍA SAN MIGUEL, Luis, El principio de igualdad, Dykinson, Madrid, 2000. 
GIDDENS, Anthony, Más allá de la izquierda y de la derecha. El futuro de las politicas radicales, Cátedra, Madrid, 1996.

LAPORTA, Francisco J., «Imperio de la ley: reflexiones sobre un punto de partida de Elías Díaz», en Doxa, 1994.

LAPORTA, Francisco J., «Globalización e imperio de la ley. Algunas dudas westfalianas», en Anales de la Cátedra Francisco Suárez, n. ${ }^{\circ}$ 39, 2005.

LAPORTA, Francisco J., El imperio de la ley: una visión actual, Trota, Madrid, 2007.

LLAMAS CASCÓN, Ángel, Los valores jurídicos como ordenamiento material, Universidad Carlos III, Madrid, 1993.

LUCAS, Javier de, «Por qué son relevantes las reivindicaciones jurídico-políticas de las minorías", en Cuadernos de Derecho Judicial, Derechos de las minorías en una sociedad multicultural, Consejo General del Poder Judicial, Madrid, 1999.

MASPERO, Emilio, Mundialización, globalización y la patria grande latinoamericana, Conferencia en la Universidad de los Trabajadores de América Latina en San Antonio de los Altos, el 6 de octubre de 2001.

PAREJO ALFONSO, Luciano, Constitución y valores del ordenamiento, Ceura, Madrid, 1991.

PECES-BARBA, Gregorio, Los valores superiores, Tecnos, Madrid, 1984.

PECES-BARBA, Gregorio, Curso de derechos fundamentales. Teoría general, Universidad Carlos III de Madrid, Boletín Oficial del Estado, Madrid, 1995.

PÉREZ GONZÁLEZ, David. E., «Solidaridad y Globalización», en AA. VV., Revista de la Facultad de Ciencias Jurídicas, n. ${ }^{\circ}$ 7, Universidad de Las Palmas de Gran Canaria, 2002.

PÉREZ LUÑO, Antonio E., «Sobre los valores fundamentadores de los derechos humanos", en PECES-BARBA, G., El fundamento de los derechos humanos, Debate, Madrid, 1989.

PISARELLO PRADOS, Gerardo, «Derechos sociales, democracia e inmigración en el constitucionalismo español: del originalismo a una interpretación sistemática y evolutiva», en AA. VV., María José Añón (editora), La universalidad de los derechos: el reto de la inmigración, Tirant lo Blanch, Valencia, 2004. 
REGIL CASTILLA, Álvaro de, «Globalizar la riqueza: justicia social en la era de la globalización, La globalización: sus estrategias y dilemas», en Revista Nexos Virtual, 2001, en:

http://www.nexos.com.mx/internos/foros/globalizacion/alvaro1.asp.

ROBINSON, Willian I., «La globalización capitalista y la transnacionalización del Estado», trabajo presentado al Taller Trasatlántico sobre Materialismo Histórico y la Globalización, Universidad de Warwick, abril de 1998.

ROSALES, José M. ${ }^{a}$ "Del altruismo espontáneo a la solidaridad organizada», en RUBIO CARRECEDO, J., ROSALES, J. M. y TOSCANO MÉNDEZ, M., Educar para la ciudadania: perspectivas éticopoliticas, Contrastes. Revista Interdisciplinar de Filosofía, suplemento 8, 2003.

SERVITJE, Lorenzo, «La globalización y sus consecuencias en la sociedad», Conferencia dictada en el VII Congreso UNIAPAC Latinoamericano, Canela, Río Grande do Sul, Brasil, en Revista Entorno, México, enero de 1998.

SPAEMANN, Robert, "Sobre el Concepto de Dignidad Humana», en Persona y Derecho, n. ${ }^{\circ}$ 19, Pamplona, 1988.

TEITELBAUM, Alejandro, «La Deuda Externa», en Revista Glocal, Política, Economía, Cultura, Sociedad, año 1, n. ${ }^{\circ}$ 6, Rodma Comunicaciones, 2000.

VERGÉS RAMÍREZ, Salvador, Derechos humanos: Fundamentación, Tecnos, Madrid, 1997. 